\title{
Sofosbuvir Use in the Setting of End-stage Renal Disease: A Single Center Experience
}

\author{
Avin Aggarwal ${ }^{1}$, Eric R. Yoo ${ }^{2}$, Ryan B. Perumpail ${ }^{1}$, George Cholankeril ${ }^{3}$, Radhika Kumari $^{1}$, \\ Tami J. Daugherty ${ }^{1}$, Alex S. Lapasaran ${ }^{4}$ and Aijaz Ahmed*1 \\ ${ }^{1}$ Division of Gastroenterology and Hepatology, Stanford University School of Medicine, Stanford, CA, USA; ${ }^{2}$ Department of \\ Medicine, University of Illinois College of Medicine, Chicago, IL, USA; ${ }^{3}$ Division of Gastroenterology and Hepatology, \\ University of Tennessee Health Sciences Center, Memphis, TN, USA; ${ }^{4}$ Digestive Health Associates, Reno, NV, USA
}

\begin{abstract}
Background and Aims: Patients with chronic hepatitis C $(\mathrm{CHC})$ and end-stage renal disease (ESRD) who are dialysisdependent form a unique group, in which safety, tolerability and efficacy of sofosbuvir (SOF)-based direct-acting antivirals (DAAs) need further evaluation. Methods: We performed a retrospective analysis of 14 patients with $\mathrm{CHC}$ and ESRD on dialysis who received 15 courses of SOF-based therapy. We evaluated dose escalation to standard-dose SOF in this proof-of-principle experience. Results: Sustained virological response (defined as undetectable viral load at 12 weeks, SVR-12) was achieved in 13 out of the $15(86.7 \%)$ treatment courses. Seven $(46.6 \%)$ patients received reduced half dose as conservative proof-of-principal to mitigate potential toxicity. In 13 out of 15 treatment courses, patients completed the designated treatment duration. One patient was treated twice and developed SVR-12 with the retreatment. One patient was lost to follow-up and counted as a non-responder. Premature discontinuations were not due to DAA-related adverse effects. There were no reports of severe adverse effects or drug interactions. Conclusion: We treated $\mathrm{CHC}$ patients with ESRD using dose escalation to standard-dose SOF in this proof-of-principle experience and achieved SVR rates comparable to general population.
\end{abstract}

Citation of this article: Aggarwal A, Yoo ER, Perumpail RB, Cholankeril G, Kumari R, Daugherty TJ, et al. Sofosbuvir use in the setting of end-stage renal disease: a single center experience. J Clin Transl Hepatol 2017;5(1):23-26. doi: 10.14218/ JCTH.2016.00060.

\section{Introduction}

The treatment for chronic hepatitis $\mathrm{C}(\mathrm{CHC})$ has been revolutionized by the advent of interferon (IFN)-free direct-acting

Keywords: Hepatitis C; End-stage renal disease; Sofosbuvir; Direct-acting antivirals.

Abbreviations: $\mathrm{CHC}$, chronic hepatitis C; IFN, interferon; DAAs, direct-acting antivirals; ESRD, end-stage renal disease; SOF, sofosbuvir; SVR, sustained virological response; RRT, renal replacement therapy; eGFR, estimated glomerular filtration rate; GT, genotype; RBV, ribavirin; $L T$, liver transplantation; $A E$, adverse effects.

Received: 7 November 2016; Revised: 10 January 2017; Accepted: 21 January 2017 *Correspondence to: Aijaz Ahmed, Division of Gastroenterology and Hepatology, Stanford University School of Medicine, 750 Welch Road, Suite \#210, Stanford, CA 94304, USA. Tel: +1-650-498-5691, Fax: +1-650-498-5692, E-mail: aijazahmed@stanford.edu antivirals (DAAs), which show unprecedented safety, tolerability and efficacy profiles. Patients with $\mathrm{CHC}$ and end-stage renal disease (ESRD) who are dialysis-dependent form a unique group in which sofosbuvir (SOF)-based DAA regimens need further evaluation. We present our experience with the use of SOF-based regimens in this subpopulation of hepatitis $\mathrm{C}$ virus (HCV)-infected patients.

\section{Methods}

We studied 14 patients with $\mathrm{CHC}$ and ESRD who received 15 courses of SOF-based regimens. One patient was treated twice and developed 12-week sustained virological response (SVR-12) with the retreatment. Patients were predominantly male $(86.7 \%$ vs. $13.3 \%$ females), Caucasian (53.3\% vs. $26.7 \%$ Hispanic vs. $13.3 \%$ African American) and on hemodialysis ( $93.3 \%$ vs. $6.7 \%$ on peritoneal dialysis). Most patients were on chronic renal replacement therapy (RRT), the course ranging from 4-132 months, except for 2 patients who started dialysis 4-12 weeks following the initiation of DAA therapy; both these patients had an estimated glomerular filtration rate (eGFR) $<30 \mathrm{~mL} / \mathrm{min} / 1.73 \mathrm{~m}^{2}$ when DAAbased therapy was started. Genotype (GT) distribution was as follows: 8 patients with GT-1 (60\%), 1 with GT-2 (7\%), 3 with GT-3 (20\%) and 2 with GT-4 (13\%). Baseline and on-treatment resistance associated variant testing were not performed. The stage of hepatic fibrosis was estimated based on findings from most recent liver biopsy, serum biochemical markers detection, or hepatic elastography performed during abdominal ultrasound and/or magnetic resonance imaging. The results indicated 3 patients $(20 \%)$ had stage F3-F4 advanced fibrosis or cirrhosis, $3(20 \%)$ had stage F1-F2 fibrosis, $6(40 \%)$ had no fibrosis (F0) and the remaining patients had no data.

Eight patients ( $57 \%$ ) had prior IFN failure ( 2 relapsers and 6 non-responders), while $6(43 \%)$ were treatment-naïve. All treatment regimens included SOF, and 4 out of 15 (26.7\%) treatment courses included ribavirin (RBV). Decision to initiate SOF-based treatment, composition of antiviral regimen and length of therapy were influenced by patient preference, viral determinants, severity of liver disease, previous treatment response, antiviral therapy deemed urgent by the nephrologist, drugs available on the market at the time antiviral therapy was initiated, hepatologist experience, and insurance approval process. Similarly, longer therapy duration (12 weeks vs. 24 weeks) was determined based on presence of cirrhosis and previous non-response. Patients with underlying cirrhosis 
Aggarwal A. et al: Sofosbuvir in patients on dialysis with HCV

Table 1. Patient profile and baseline characteristics

\begin{tabular}{|c|c|}
\hline \multicolumn{2}{|l|}{ Patient characteristics } \\
\hline Age in years, mean (SD) & $61(4.9)$ \\
\hline \multicolumn{2}{|l|}{ Sex, $n(\%)$} \\
\hline M & $13(86.7)$ \\
\hline $\mathrm{F}$ & $2(13.3)$ \\
\hline \multicolumn{2}{|l|}{ Ethnicity, n (\%) } \\
\hline Caucasian & $8(53.3)$ \\
\hline Hispanic/Latino & $4(26.7)$ \\
\hline African American & $2(13.3)$ \\
\hline Unknown & $1(6.7)$ \\
\hline $\begin{array}{l}\text { eGFR in } \mathrm{mL} / \mathrm{min} / 1.73 \mathrm{~m}^{2} \text {, } \\
\text { mean (SD) }\end{array}$ & $11.2(6.3)$ \\
\hline \multicolumn{2}{|l|}{ ESRD etiology, $n$ (\%) } \\
\hline HTN/DM & $5(33.3)$ \\
\hline HRS & $4(26.7)$ \\
\hline CNI toxicity & $1(6.7)$ \\
\hline MPGN/cryoglobulinemia & $3(20)$ \\
\hline Others & $2(13.3)$ \\
\hline \multicolumn{2}{|l|}{ Type of dialysis } \\
\hline Hemodialysis & $14(93.3)$ \\
\hline Peritoneal & $1(6.7)$ \\
\hline $\begin{array}{l}\text { Duration of dialysis prior to therapy } \\
\text { in months, range (min-max) }\end{array}$ & $128(4-132)$ \\
\hline \multicolumn{2}{|l|}{ Genotype, n (\%) } \\
\hline GT1 & $9(60)$ \\
\hline GT2 & $1(6.7)$ \\
\hline GT3 & $3(20)$ \\
\hline GT4 & $2(13.3)$ \\
\hline \multicolumn{2}{|l|}{$\begin{array}{l}\text { Most recent fibrosis stage determined by } \\
\text { pathology/Fibroscan/Fibrosure, } n(\%)\end{array}$} \\
\hline FO & $6(40)$ \\
\hline $\mathrm{F} 1-\mathrm{F} 2$ & $3(20)$ \\
\hline F3-F4/cirrhosis & $3(20)$ \\
\hline \multicolumn{2}{|l|}{ Prior therapy, n (\%) } \\
\hline Treatment-naïve & $6(40)$ \\
\hline IFN & $8(53.3)$ \\
\hline IFN and DAA & $1(6.7)$ \\
\hline Ribavirin use, $n$ (\%) & $4(26.7)$ \\
\hline SOF dose reduction, $n(\%)$ & $7(46.7)$ \\
\hline \multicolumn{2}{|l|}{ Duration of therapy, $n(\%)$} \\
\hline$<12$ weeks & $2(13.3)$ \\
\hline 12 weeks & $8(53.3)$ \\
\hline 24 weeks & $5(33.3)$ \\
\hline Post-liver transplant status, $n(\%)$ & $6(40)$ \\
\hline \multicolumn{2}{|l|}{ Pre-therapy laboratory values } \\
\hline Baseline HCV RNA in IU/mL, mean (SD) & $\begin{array}{l}8375588.6 \\
(12523305)\end{array}$ \\
\hline
\end{tabular}

\begin{tabular}{|c|c|}
\hline Patient characteristics & \\
\hline Serum albumin in $\mathrm{g} / \mathrm{dL}$, mean (SD) & $3.5(0.6)$ \\
\hline INR, mean (SD) & $1.2(0.34)$ \\
\hline AST in IU/mL, mean (SD) & $45.4(31.1)$ \\
\hline ALT in $\mathrm{IU} / \mathrm{mL}$, mean (SD) & $43(26.6)$ \\
\hline ALP in $\mathrm{IU} / \mathrm{mL}$, mean (SD) & $385.3(593.5)$ \\
\hline Total bilirubin in $\mathrm{mg} / \mathrm{dL}$, mean (SD) & $0.99(0.6)$ \\
\hline Serum creatinine in $\mathrm{mg} / \mathrm{dL}$, mean (SD) & $5.4(1.7)$ \\
\hline Hemoglobin in $\mathrm{g} / \mathrm{dL}$, mean (SD) & $11.1(1.9)$ \\
\hline Concomitant tacrolimus, $n(\%)$ & $6(40)$ \\
\hline
\end{tabular}

Abbreviation: SD, standard deviation.

and previous history of treatment failure were treated for 24 weeks with the SOF-based regimen. Six patients (43\%) were treated following liver transplantation (LT) in the setting of tacrolimus-based immunosuppression.

Baseline mean $( \pm S D)$ biochemical laboratory values and characteristics are summarized in Table 1. HCV RNA level was measured by quantitative real-time polymerase chain reaction-based $\mathrm{HCV}$ test $\left(\mathrm{COBAS}^{\mathrm{R}}\right.$ AmpliPrep/COBAS $^{\mathrm{R}}$ $\operatorname{TaqMan}^{R}$ HCV Test v2.0). Since no guidelines existed for SOF dosing in ESRD patients, we chose to administer half dose $(200 \mathrm{mg})$ taken orally once daily - by splitting the SOF tablet in half. The first 7 out of $15(46.6 \%)$ treatment courses used the reduced $200 \mathrm{mg}$ per day dose as conservative proofof-principal to mitigate potential toxicity associated with exposure to free nucleoside derivative of SOF. ${ }^{1,2}$ Two patients were switched to full-dose ( $400 \mathrm{mg}$ once daily) SOF dosing at 4-6 weeks after initiation of the antiviral therapy, irrespective of total length of therapy and based on the hepatologist's preference. These patients were treated by 3 hepatologists at a tertiary care center. Prior to starting the SOF-based treatment, a detailed and comprehensive discussion was conducted with each patient regarding the potential risks of pursuing off-label therapy. Each patient was informed and understood that data regarding the use of SOF in individuals with severe renal impairment were lacking.

\section{Results}

In 13 out of 15 treatment courses, patients completed the designated treatment duration, with 2 out of 15 treatments stopped prematurely. One of those 2 patients stopped therapy at week 8 , due to prosthetic knee graft infection and related sepsis, but still developed SVR-12. The second patient with premature treatment discontinuation suffered a massive cerebrovascular accident at week 4; he was subsequently lost to follow-up and considered a non-responder in our analysis. None of the treatment discontinuations were deemed therapyrelated. In total, 13 out of 14 patients successfully reached SVR-12 (92.8\%), representing 13 out of 15 treatment courses $(86.6 \%)$. Only 1 patient relapsed after completing 12 weeks of antiviral therapy using half dose SOF plus simeprevir. He was successfully retreated for 24 weeks with standard-dose SOF plus ledipasvir co-formulation and developed SVR-12.

The SOF-based regimens included SOF and simeprevir $(n=6,40 \%)$, SOF and ledipasvir co-formulation $(n=4,27 \%)$, SOF and RBV $(n=2,13 \%)$, SOF and ledipasvir co-formulation plus RBV $(n=1,6.3 \%)$, SOF, RBV and PEGylated-IFN $(n=1$, 
$6.3 \%)$, and SOF and daclatasvir ( $n=1,6.3 \%)$. RBV dose was restricted to no more than $200 \mathrm{mg}$ per day. There were no significant changes in hemoglobin levels associated with low-dose RBV. None of the patients experienced hepatic decompensation or complications related to RRT during SOF exposure.

Minor adverse effects (AEs) observed were headache in $1(0.06 \%)$, acid reflux in $1(0.06 \%)$, and fatigue in $3(20 \%)$, of which 2 had chronic fatigue at baseline prior to starting SOF-based therapy. Two patients (13.3\%) developed anemia, only 1 of whom being transfusion-dependent in the setting of critical sepsis and concomitant RBV use. The other patient with anemia was not taking RBV, but was recently placed on hemodialysis with worsening of ESRD, making anemia of chronic disease as a likely etiology. None of the patients developed severe AEs or drug-drug interactions with their concomitant tacrolimus-based immunosuppression.

Laboratory data following completion of the antiviral therapy showed mean hemoglobin of $11.6 \mathrm{~g} / \mathrm{dL}( \pm 2.2)$, no rise in serum total bilirubin $(0.7 \pm 0.2 \mathrm{mg} / \mathrm{dL})$, and overall improvement in liver enzymes (Table 2 ). Cryoglobulinemia in 3 patients did not resolve at 6 months, despite a favorable response. As expected, none of the dialysis-dependent patients demonstrated improvement in renal function at 3- and 6-month follow-up visits, except for 1 patient who was lost to follow-up. There were no significant differences in laboratory parameters before and after antiviral therapy, except for normalization of liver enzymes in patients with SVR-12.

\section{Discussion}

Compared to the general population, there is a higher prevalence of $\mathrm{CHC}$ in patients with ESRD (defined as eGFR $\left.<30 \mathrm{~mL} / \mathrm{min} / 1.73 \mathrm{~m}^{2}\right){ }^{3,4}$ especially in those undergoing hemodialysis who have an approximately 5 -fold higher seroprevalence $\left(7.8 \%\right.$ vs. $1.6 \%$ in general population)..$^{5,6} \mathrm{CHC}$ has a significant negative impact on mortality and morbidity in dialysis-dependent patients, not only from liver-related complications, ${ }^{7-10}$ but also from increased extra-hepatic comorbidities. ${ }^{11}$ Historically, IFN-based regimens had suboptimal cure rates and poor tolerability, leading to treatment discontinuation. Only a few case reports and case series have explored the use of first generation protease inhibitors in combination with IFN and RBV in ESRD patients on RRT; ${ }^{12,13}$ these analyses consistently reported poor tolerance leading to higher dropout rates and lack of response. ${ }^{14}$

Withholding $\mathrm{CHC}$ therapy in patients on maintenance dialysis wait-listed for renal transplantation can lead to progression of liver disease, ${ }^{15}$ particularly in those with early-stage fibrosis and potential need for simultaneous liver-kidney transplantation. SOF was first among its class of nonstructural protein $5 \mathrm{~B}$ polymerase inhibitors to be introduced and revolutionized $\mathrm{CHC}$ treatment. SOF is mainly cleared renally, and studies have shown $456 \%$ higher levels of its major systemic metabolite (GS-331007) in individuals with severe renal dysfunction as compared with those with normal renal function. ${ }^{16}$ Future studies are needed to evaluate the safety and efficacy of SOF-based regimens in individuals with ESRD, especially those on RRT.

Several centers have reported their experiences. Nazario et al. ${ }^{17}$ treated 17 ( 2 out of the 17 following liver transplantation) genotype-1a hemodialysis-dependent patients with 12 weeks of SOF and simeprevir therapy and reported $100 \%$ SVR-12 without any therapy-related AE. Another case series
Table 2. Therapy efficacy and safety characteristics

\begin{tabular}{|c|c|}
\hline \multicolumn{2}{|l|}{ Therapy efficacy characteristics } \\
\hline $\begin{array}{l}\text { Early treatment discontinuation, } n \\
\text { (total, \%) }\end{array}$ & $2(15,13.3)$ \\
\hline End-treatment response, $n,(\%)$ & $14(100)$ \\
\hline $\begin{array}{l}\text { Sustained virological response-12 weeks, } \\
n(\%)\end{array}$ & $13(92.8)$ \\
\hline Relapse, $n(\%)$ & $1(0.06)$ \\
\hline \multicolumn{2}{|l|}{ Therapy safety characteristics } \\
\hline Post-therapy laboratory values & Mean (SD) \\
\hline Serum albumin in $\mathrm{g} / \mathrm{dL}$ & $3.6(0.9)$ \\
\hline INR* & $1.2(0.2)$ \\
\hline AST in IU/mL & $21.5(7)$ \\
\hline ALT in IU/mL & $20(14.6)$ \\
\hline ALP in $\mathrm{IU} / \mathrm{mL}$ & $\begin{array}{l}119.7 \\
(86.3)\end{array}$ \\
\hline Total bilirubin in $\mathrm{mg} / \mathrm{dL}$ & $0.7(0.2)$ \\
\hline Serum creatinine in $\mathrm{mg} / \mathrm{dL}$ & $5.5(1.9)$ \\
\hline Hemoglobin in $\mathrm{g} / \mathrm{dL}$ & $11.6(2.2)$ \\
\hline Mild AE, related/unrelated, on therapy & $n,(\%)$ \\
\hline Headache & $1(0.06)$ \\
\hline Fatigue & $3(20)$ \\
\hline Acid reflux & $1(0.06)$ \\
\hline $\begin{array}{l}\text { Anemia as } \geq 2 \mathrm{~g} / \mathrm{dL} \text { decrease in } \\
\text { hemoglobin }\end{array}$ & $2(13.3)$ \\
\hline Treatment interruptions due to $\mathrm{AE}$ & None \\
\hline Hospitalizations due to AE & None \\
\hline Death/lost to follow-up & $1(0.06)$ \\
\hline Complications with dialysis & None \\
\hline $\begin{array}{l}\text { Any interaction with tacrolimus, if } \\
\text { applicable }\end{array}$ & None \\
\hline
\end{tabular}

*Post-therapy INR not available for 2 patients.

Abbreviation: $A E$, adverse effects.

by Kalyan et al. ${ }^{18}$ showed that 12 out of 15 patients with GT1 on RRT and treated with half-dose SOF developed SVR-12 $(87 \%)$. Interestingly, lower SVR rates were almost always related to underlying cirrhosis. None of the patients in this series were transplant recipients. The longitudinal "real world" multicenter HCV-TARGET study included a large pangenotypic patient cohort with renal insufficiency, including liver transplant recipients, treating them with full-dose SOFcontaining therapy and achieving comparable SVR rates to overall SVR (88\%); although higher frequency of anemia was noted irrespective of RBV use, worsening renal function and higher rates of $\mathrm{AE}$ were noted in groups with advanced renal impairment. ${ }^{19}$ Beinhardt et al. ${ }^{20}$ also recently reported a $96 \%$ rate of SVR-12 on SOF-based regimens in a study of 24 patients, 10 of whom were on RRT, 8 of whom were kidney transplant recipients, and 7 of whom were liver-kidney transplant recipients.

Use of new DAAs in the post-transplant setting requires knowledge of drug-drug interactions with common immunosuppressive agents, mainly calcineurin inhibitors. Our study consisted of $40 \%$ post-transplant patients who were treated 
in a real world clinical practice setting with SOF-based DAAs. There were also no drug-drug interactions or need for immunosuppression dose adjustments to maintain therapeutic peak/ trough levels in our study patients. A recent study reported acceptable efficacy, with SVR rate of $70 \%$ (90\%, CI $56-82 \%)$, and good tolerability without interactions of SOF and RBVbased therapy with tacrolimus, mycophenolate, prednisone, cyclosporine or azathioprine in LT recipients. ${ }^{20}$ As newer agents continue to emerge in the DAA category, promising data is surfacing from studies like C-SURFER and RUBY-1 that show high cure rates and favorable safety profiles for these drugs in this particular patient population. ${ }^{21,22}$ Therefore, it is important to recognize that other agents have been licensed in the USA and Europe with excellent safety profiles in the setting of ESRD. Based on our experience, the SOF-based regimen is a safe and effective alternative if other agents are not available.

\section{Conclusions}

SOF, a prodrug efficiently extracted by first-pass hepatic uptake, avoids significant renal excretion. In the liver, SOF is metabolized to the uridine monophosphate that can either be further phosphorylated to the active triphosphate form (GS-461203), a uridine triphosphate analog of the HCV NS5B polymerase, ${ }^{3}$ or be dephosphorylated to the free nucleoside. The free nucleoside enters the circulation and is excreted primarily in the urine. Current guidelines recommend avoiding SOF therapy in patients with severe renal dysfunction. However, we treated our patients with dose escalation to standard-dose SOF in this proof-of-principle experience because the active triphosphate levels in the liver should be equivalent in patients with or without renal disease.

Our experience provides meaningful insight into applying the remarkable efficacy data reported in registration trials for SOF in a real-life practice setting not addressed in those trials. As with most retrospective studies, prospective studies are warranted to further validate our observations. We await the results of ongoing studies using SOF in patients on hemodialysis with different dosing schedules.

\section{Conflict of interest}

Aijaz Ahmed is a consultant and advisory board member for AbbVie Pharmaceuticals, Gilead Sciences, and Janssen Pharmaceutical, and has research funding/grant from Gilead Sciences. The other authors have nothing to disclose.

\section{Author contributions}

Study concept and design (AA, ERY, RBP, GC, RK, TJD, ASL, $A A)$, acquisition of data (AA, ERY, RBP, GC, AA), analysis and interpretation of data (AA, ERY, RBP, GC, RK, TJD, ASL, AA), drafting of the initial and final manuscript (AA, ERY, RBP, GC, $A A)$, critical revision of the manuscript (AA, ERY, RBP, GC, RK, TJD, ASL, AA), and study supervision (AA).

\section{References}

[1] Perumpail RB, Wong RJ, Ha LD, Pham EA, Wang U, Luong H, et al. Sofosbuvir and simeprevir combination therapy in the setting of liver transplantation and hemodialysis. Transpl Infect Dis 2015;17:275-278. doi: 10.1111/tid.12348.
[2] Perumpail RB, Wong RJ, Pham EA, Higgins JP, Daugherty TJ, Ahmed A. A new standard of care? standard dose sofosbuvir in an HCV-infected liver transplant recipient undergoing hemodialysis. Dig Dis Sci 2016;61:39-41. doi: 10.1007/s10620-015-3756-z.

[3] Berenguer M. Treatment of chronic hepatitis $C$ in hemodialysis patients. Hepatology 2008;48:1690-1699. doi: 10.1002/hep.22545.

[4] Fabrizi F, Poordad FF, Martin P. Hepatitis $C$ infection and the patient with endstage renal disease. Hepatology 2002;36:3-10. doi: 10.1053/jhep.2002. 34613.

[5] Carrion AF, Martin P. What are the management issues for hepatitis $C$ in dialysis patients?: natural history of hepatitis $C$ in dialysis populations. Semin Dial 2014;27:446-448. doi: 10.1111/sdi.12292.

[6] Finelli L, Miller JT, Tokars JI, Alter MJ, Arduino MJ. National surveillance of dialysis-associated diseases in the United States, 2002. Semin Dial 2005; 18 : 52-61. doi: 10.1111/j.1525-139X.2005.18108.x.

[7] Fabrizi F, Lunghi G, Ganeshan SV, Martin P, Messa P. Hepatitis C virus infection and the dialysis patient. Semin Dial 2007;20:416-422. doi: 10.1111/j.1525139x.2007.00311.x.

[8] Fabrizi F, Takkouche B, Lunghi G, Dixit V, Messa P, Martin P. The impact of hepatitis $C$ virus infection on survival in dialysis patients: meta-analysis of observational studies. J Viral Hepat 2007;14:697-703. doi: 10.1111/j.13652893.2007.00868.x.

[9] Liu CH, Kao JH. Treatment of hepatitis $\mathrm{C}$ virus infection in patients with endstage renal disease. J Gastroenterol Hepatol 2011;26:228-239. doi: 10. 1111/j.1440-1746.2010.06488.x.

[10] Okoh EJ, Bucci JR, Simon JF, Harrison SA. HCV in patients with end-stage renal disease. Am J Gastroenterol 2008;103:2123-2134. doi: 10.1111/j. 1572-0241.2008.01981.x.

[11] Fabrizi F, Messa P, Martin P. Recent advances on hepatitis $C$ virus in dialysis population. Kidney Blood Press Res 2014;39:260-271. doi: 10.1159/ 000355803.

[12] Dumortier J, Guillaud O, Gagnieu MC, Janbon B, Juillard L, Morelon E, et al. Anti-viral triple therapy with telaprevir in haemodialysed HCV patients: is it feasible? J Clin Virol 2013;56:146-149. doi: 10.1016/j.jcv.2012.10.009.

[13] Lemoinne S, Barrou B, Thabut D. Triple therapy for hepatitis $C$ virus infection in patients receiving hemodialysis. Ann Intern Med 2014;160:581. doi: 10. 7326/L14-5008-3.

[14] Goodkin DA, Bieber B, Gillespie B, Robinson BM, Jadoul M. Hepatitis C infection is very rarely treated among hemodialysis patients. Am J Nephrol 2013; 38:405-412. doi: 10.1159/000355615.

[15] Fabrizi F, Messa P. Therapy of hepatitis $C$ by direct-acting anti-virals: the end of HCV in dialysis population? Expert Rev Clin Pharmacol 2015;8:785-793. doi: $10.1586 / 17512433.2015 .1086266$.

[16] Cornpropst MT, Denning JM, Clemons D, Marbury TC, Alcorn H, Smith WB, et al. The effect of renal impairment and end stage renal disease on the single-dose pharmacokinetics of PSI-7977. J Hepatol 2012;56:S433. doi: 10.1016/S0168-8278(12)61113-1.

[17] Nazario HE, Ndungu M, Modi AA. Sofosbuvir and simeprevir in hepatitis C genotype 1-patients with end-stage renal disease on haemodialysis or GFR $<30 \mathrm{ml} / \mathrm{min}$. Liver Int 2016;36:798-801. doi: 10.1111/liv.13025.

[18] Bhamidimarri KR, Czul F, Peyton A, Levy C, Hernandez M, Jeffers L, et al. Safety, efficacy and tolerability of half-dose sofosbuvir plus simeprevir in treatment of Hepatitis $C$ in patients with end stage renal disease. J Hepatol 2015;63:763-765. doi: 10.1016/j.jhep.2015.06.004.

[19] Saxena V, Koraishy FM, Sise ME, Lim JK, Schmidt M, Chung RT, et al. Safety and efficacy of sofosbuvir-containing regimens in hepatitis C-infected patients with impaired renal function. Liver Int 2016;36:807-816. doi: 10 . 1111/liv.13102.

[20] Charlton M, Gane E, Manns MP, Brown RS Jr, Curry MP, Kwo PY, et al. Sofosbuvir and ribavirin for treatment of compensated recurrent hepatitis $C$ virus infection after liver transplantation. Gastroenterology 2015;148:108-117. doi: 10.1053/j.gastro.2014.10.001.

[21] Roth D, Nelson DR, Bruchfeld A, Liapakis A, Silva M, Monsour H Jr, et al. Grazoprevir plus elbasvir in treatment-naive and treatment-experienced patients with hepatitis $C$ virus genotype 1 infection and stage 4-5 chronic kidney disease (the C-SURFER study): a combination phase 3 study. Lancet 2015;17;386:1537-1545. doi: 10.1016/S0140-6736(15)00349-9.

[22] Pockros PJ, Reddy KR, Mantry PS, Cohen E, Bennett M, Sulkowski MS, et al. Safety of ombitasvir/paritaprevir/ritonavir plus dasabuvir for treating HCV GT1 infection in patients with severe renal impairment or end-stage renal disease: the RUBY-1 Study. J Hepatol 2015;62:S257. doi: 10.1016/S01688278(15)30147-1. 